\title{
Analysis of the Isomerase and Chaperone-Like Activities of an Amebic PDI (EhPDI)
}

\author{
Rosa E. Mares, Alexis Z. Minchaca, Salvador Villagrana, \\ Samuel G. Meléndez-López, and Marco A. Ramos
}

Facultad de Ciencias Químicas e Ingeniería, Universidad Autónoma de Baja California, Calzada Universidad 14418, Parque Industrial Internacional, 22390 Tijuana, BCN, Mexico

Correspondence should be addressed to Marco A. Ramos; mramos@uabc.edu.mx

Received 10 August 2014; Revised 20 November 2014; Accepted 24 November 2014

Academic Editor: Yun-Peng Chao

Copyright (C) 2015 Rosa E. Mares et al. This is an open access article distributed under the Creative Commons Attribution License, which permits unrestricted use, distribution, and reproduction in any medium, provided the original work is properly cited.

Protein disulfide isomerases (PDI) are eukaryotic oxidoreductases that catalyze the formation and rearrangement of disulfide bonds during folding of substrate proteins. Structurally, PDI enzymes share as a common feature the presence of at least one active thioredoxin-like domain. PDI enzymes are also involved in holding, refolding, and degradation of unfolded or misfolded proteins during stressful conditions. The EhPDI enzyme (a $38 \mathrm{kDa}$ polypeptide with two active thioredoxin-like domains) has been used as a model to gain insights into protein folding and disulfide bond formation in E. histolytica. Here, we performed a functional complementation assay, using a $\Delta d s b \mathrm{C}$ mutant of $E$. coli, to test whether EhPDI exhibits isomerase activity in vivo. Our preliminary results showed that EhPDI exhibits isomerase activity; however, further mutagenic analysis revealed significant differences in the functional role of each thioredoxin-like domain. Additional studies confirmed that EhPDI protects heat-labile enzymes against thermal inactivation, extending our knowledge about its chaperone-like activity. The characterization of EhPDI, as an oxidative folding catalyst with chaperone-like function, represents the initial step to dissect the molecular mechanisms involved in protein folding in E. histolytica.

\section{Introduction}

In eukaryotic cells, folding and posttranslational modifications of proteins are the primary function of the endoplasmic reticulum (ER) [1]. Formation of disulfide bonds, a common modification observed in several secretory proteins, takes place mainly in that compartment $[1,2]$. Almost all organisms have a set of proteins involved in folding; however, the cellular and molecular details of this process have been elucidated only in a few model systems, such as the yeast ER and the bacterial periplasmic compartment $[3,4]$.

Protein disulfide isomerases (PDI) are eukaryotic oxidoreductases that catalyze the formation and rearrangement of disulfide bonds during folding of substrate proteins [5]. Structurally, PDI enzymes share as a common feature the presence of at least one active thioredoxin-like domain. Some organisms, such as yeast and mammals, have a family of PDI homologues that exhibit distinct domain organization and function [6-8].
Under physiological conditions, the cellular mechanisms that respond to proteotoxic stress remain in an inactive state; however, under stressful conditions, several response mechanisms are triggered to restore proteome stability, but if these fail, the apoptotic pathways are activated, leading ultimately to cell death $[9,10]$. In addition to assisting oxidative folding of nascent polypeptides, PDI enzymes are also involved in holding, refolding, and degradation of unfolded or misfolded proteins under stressful conditions [10]. Furthermore, since the blocking of PDI activity could lead to protein misfolding, prolonged proteotoxic stress and apoptosis $[11,12]$ considering PDI as a therapeutic target to stop the progression of some diseases seem plausible $[13,14]$.

Human amebiasis, the parasitic infection caused by the protozoan Entamoeba histolytica, is a prevalent infection in developing countries [15]. Interestingly, the continued secretion of proteins, including virulence factors, is well recognized as the primary feature of this parasite [16]. Moreover, protein folding and correct disulfide bond formation 
TABLE 1: Strains and plasmids used in this study.

\begin{tabular}{|c|c|c|}
\hline Strains or plasmids & Relevant genotype or features & $\begin{array}{l}\text { Source or } \\
\text { reference }\end{array}$ \\
\hline \multicolumn{3}{|l|}{ Strains } \\
\hline XL1-Blue MRF ${ }^{\prime}$ & $\begin{array}{l}\Delta(m c r A) 183 \Delta(m c r C B-h s d S M R-m r r) 173 \text { end A1 supE44 thi-1 recA1 gyrA96 relA1 lac }\left[F^{\prime} \text { proAB }\right. \\
\left.\text { lacI }^{q} Z \Delta M 15 \text { Tn10 }\left(\text { Tet }^{R}\right)\right]\end{array}$ & Stratagene \\
\hline Shuffle Express & 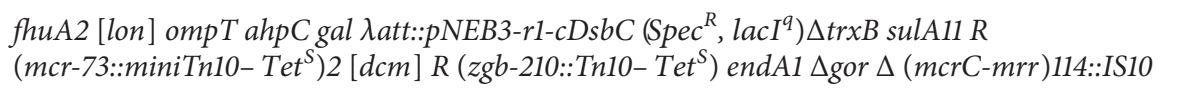 & $\mathrm{NEB}^{1}$ \\
\hline BW25113 & $F^{-} \Delta($ araD-araB $) 567 \Delta l a c Z 4787(:: r r n B-3) \lambda^{-}$rph-1 $\Delta($ rhaD-rhaB $) 568$ hsdR514 & $\begin{array}{c}\mathrm{CGSC}^{2} \\
{[54]}\end{array}$ \\
\hline JW2861-1 & BW25113 dsbC744::kan & $\begin{array}{c}\mathrm{GCSC}^{2} \\
{[54]}\end{array}$ \\
\hline \multicolumn{3}{|l|}{ Plasmid } \\
\hline pBAD33 & Arabinose regulation, p15A origin, $\mathrm{Cm}^{\mathrm{R}}$ & $\begin{array}{l}\mathrm{ATCC}^{3} \\
{[55]}\end{array}$ \\
\hline pBAD-AppA & pBAD33-based, periplasmic AppA & This study \\
\hline pBluescript SK- & Lactose regulation, ColE1 origin, $\mathrm{Amp}^{\mathrm{R}}$ & Stratagene \\
\hline pBAppA & pBluescript-based, periplasmic AppA & This study \\
\hline pBPelB-EhPDI & pBluescript-based, periplasmic EhPDI (wild type) & {$[22]$} \\
\hline pBRM05 & pBluescript-based, periplasmic EhPDI $\mathrm{SS} / \mathrm{CC}(\mathrm{C} 44 \mathrm{~S} ; \mathrm{C} 47 \mathrm{~S})$ & {$[20]$} \\
\hline pBRM06 & pBluescript-based, periplasmic EhPDI $\mathrm{CC} / \mathrm{sS}(\mathrm{C} 160 \mathrm{~S} ; \mathrm{C} 163 \mathrm{~S})$ & {$[20]$} \\
\hline pBRM15 & pBluescript-based, periplasmic EhPDI $\mathrm{SS}_{\mathrm{SS}}(\mathrm{C} 44 \mathrm{~S} ; \mathrm{C} 47 \mathrm{~S} ; \mathrm{C} 160 \mathrm{~S} ; \mathrm{C} 163 \mathrm{~S})$ & {$[20]$} \\
\hline pQE30 & Lactose regulation, ColE1 origin, $A m p^{R}$ & Qiagen \\
\hline pQHPDI & pQE30-based, recombinant EhPDI (wild type) & {$[20]$} \\
\hline pQRM05 & pQE30-based, recombinant EhPDI ${ }_{\mathrm{SS} / \mathrm{CC}}(\mathrm{C} 44 \mathrm{~S} ; \mathrm{C} 47 \mathrm{~S})$ & This study \\
\hline pQRM06 & pQE30-based, recombinant EhPDI $\mathrm{CC} / \mathrm{SS}(\mathrm{C} 160 \mathrm{~S} ; \mathrm{C} 163 \mathrm{~S})$ & This study \\
\hline pQRM15 & pQE30-based, recombinant EhPDI ${ }_{\mathrm{SS} / \mathrm{SS}}(\mathrm{C} 44 \mathrm{~S}$; C47S; C160S; C163S) & This study \\
\hline
\end{tabular}

${ }^{1}$ New England Biolabs; ${ }^{2}$ Coli Genetic Stock Center; ${ }^{3}$ American Type Culture Collection.

are essential for secreted virulence factors, such as the Gal/GalNAc-inhibitable lectin [17] and the pore-forming peptide A (amoebapore A) [18].

The E. histolytica genome has 11 genes encoding PDI homologues [19]. From these, the enzyme named EhPDI (a 38 $\mathrm{kDa}$ polypeptide with two active thioredoxin-like domains) has been used as a model to study protein folding and disulfide bond formation in E. histolytica. By using in vitro assays and standard substrates (such as insulin, lysozyme, and ribonuclease A), we have confirmed that EhPDI exhibits the distinctive oxidoreductase activities (reductase, oxidase, and isomerase) as well as the typical chaperone-like function (suppression of polypeptide aggregation) [20, 21]. Only the oxidase activity has been demonstrated in vivo, through functional complementation of the $d s b \mathrm{~A}$ mutation in $E$. coli [22].

Here, to test whether EhPDI exhibits isomerase activity in vivo, we performed a functional complementation assay using the $\Delta d s b \mathrm{C}$ mutant of $E$. coli as a model and the defective expression of the periplasmic protein AppA as the phenotype. The acid phosphatase-phytase enzyme (AppA) has three consecutive disulfide bonds and one nonconsecutive that renders it dependent on DsbC [23]. Our preliminary results showed that EhPDI exhibits isomerase activity; however, further mutagenic analysis revealed significant differences in the functional role of each thioredoxin-like domain. Finally, additional studies confirmed that EhPDI protects two heatlabile enzymes, $\alpha$-glucosidase and $\mathrm{NdeI}$ endonuclease, against thermal inactivation, extending our knowledge about its chaperone-like activity.

\section{Materials and Methods}

2.1. Materials. DNA amplification reagents and DNA purification kits were from Qiagen (Valencia, CA). Bacterial media were from Becton Dickinson (Franklin Lakes, NJ). Electrophoresis reagents were from Bio-Rad (Hercules, CA). Endonucleases and other enzymes were from New England Biolabs (Ipswich, MA). Other biochemicals were from Sigma-Aldrich (St. Louis, MO), otherwise mentioned in the text. All reagents used were analytical or molecular biology grade.

2.2. Bacterial Strains, Plasmids, and Growth Conditions. Escherichia coli strains and plasmids used in this study are listed in Table 1. Bacterial cultures were grown in LB medium 
at $37^{\circ} \mathrm{C}$, with appropriate antibiotics (ampicillin at $150 \mu \mathrm{g} / \mathrm{mL}$ and chloramphenicol at $15 \mu \mathrm{g} / \mathrm{mL}$ ). Recombinant plasmids were constructed by using standard molecular cloning protocols.

2.2.1. Construction of $p B A D-A p p A$ Plasmid. Full-length sequence of the bacterial appA gene was amplified from genomic DNA (XL1-Blue $\mathrm{MRF}^{\prime}$ strain), using the synthetic oligonucleotides EcAppAF $\left(5^{\prime}-\mathrm{cgc}\right.$ gcg gaa ttc ATG AAA AGC GGA AAC ATA TCG-3 $\left.{ }^{\prime}\right)$ and EcAppAR ( $5^{\prime}$-cgc gcg tct aga TTA CAA ACT GCA CGC CGG TAT- $3^{\prime}$ ) as primers. The PCR product was then digested with EcoRI and XbaI endonucleases and cloned into the EcoRI-XbaI sites of pBluescript SK-, yielding the pBAppA plasmid. To obtain the pBAD-AppA plasmid, a site for EcoRV (located immediately upstream of the EcoRI) was used to get a restriction fragment from EcoRV-XbaI sites, which was then subcloned into SmaI-XbaI sites of pBAD33. The appA gene was confirmed by DNA sequencing.

2.2.2. Construction of the $p Q R M 05, p Q R M 06$, and $p Q R M 15$ Plasmids. The EhPDI gene variants (with Cys to Ser substitutions) were amplified from its corresponding pBluescriptbased plasmid (Table 1), using the synthetic oligonucleotides EhPDIp38F ( $5^{\prime}$-cat cac gga tcc GCT GAT GTA GTA TCA TTA AAT C- $\left.3^{\prime}\right)$ and M13FW ( $5^{\prime}$-GTA AAA CGA CGG CCA GTG- $3^{\prime}$ ) as primers. Then, PCR products were digested with BamHI and HindIII endonucleases and subcloned into the same sites of pQE30 (in frame with the sequence encoding the N-terminal hexahistidine tag). The EhPDI gene variants were confirmed by DNA sequencing.

\subsection{DsbC Complementation and AppA Activity Assay}

2.3.1. Periplasmic Expression of AppA and Coexpression with EhPDI. E. coli strains BW25113 (wild type) and JW2861-1 ( $\Delta d s b \mathrm{C}$ mutant) were transformed with pBAD33 (as control) or pBAD-AppA. Stable transformants were cultured in LB medium, supplemented with chloramphenicol, and the periplasmic expression of AppA was induced with $0.2 \%$ arabinose. Bacterial cell pellets (from $1 \mathrm{~mL}$ ) were obtained by centrifugation (2 $\mathrm{min}$ at 10,000 rpm).

E. coli strain JW2861-1 harboring pBAD-AppA was transformed with pBluescript-based plasmids expressing EhPDI variants (Table 1). The plasmid pBluescript SK- was used as a control. Stable cotransformants were cultured in LB medium, supplemented with ampicillin and chloramphenicol, and the periplasmic coexpression of AppA and EhPDI was induced with $0.2 \%$ arabinose and $1 \mathrm{mM}$ IPTG. Bacterial cell pellets were obtained as before.

2.3.2. Acid Phosphatase Activity Assay. The acid phosphatase activity was determined by a colorimetric assay [23]. Bacterial cell pellets were resuspended in glycine buffer $(0.25 \mathrm{M} ; \mathrm{pH}$ 2.5 ) and adjusted to $0.3-0.6$ units of $A_{600}$ per mL. Then, $20 \mu \mathrm{L}$ aliquots were further diluted with $80 \mu \mathrm{L}$ of the same buffer and mixed with $100 \mu \mathrm{L}$ of $50 \mathrm{mM} p$-nitrophenyl phosphate. After $15 \mathrm{~min}$ of incubation at $37^{\circ} \mathrm{C}$, reactions were stopped by adding $1 \mathrm{~mL}$ of $1.2 \mathrm{~N} \mathrm{NaOH}$. Immediately, supernatants were separated by centrifugation ( $5 \mathrm{~min}$ at $14,500 \mathrm{rpm}$ ) and the released $p$-nitrophenolate was quantified by measuring the $A_{420}$. Light scattering by cellular debris was also considered (recording the $A_{550}$ ). The acid phosphatase activity was expressed in Miller units [23, 24].

2.4. Purification of Recombinant EhPDI Enzymes. E. coli strain Shuffle Express was transformed with pQE30-based plasmids expressing recombinant EhPDI enzyme variants (see Table 1). Stable transformants were cultured in LB medium, supplemented with ampicillin, and protein expression was induced with $0.1 \mathrm{mM}$ IPTG. Bacterial cells (from $100 \mathrm{~mL}$ ) were harvested and lysed under native conditions, using the CelLytic B Plus Kit (Sigma-Aldrich). From the soluble fraction, recombinant proteins were purified by $\mathrm{Ni}$ affinity chromatography (The QIAexpressionist, Qiagen). Eluate fractions were analyzed by SDS-PAGE and those containing more than $95 \%$ of pure protein were pooled and concentrated/desalted by ultrafiltration, using a Microsep UF Spin Filter (Pall Co.). Protein concentration was determined by performing the BCA colorimetric assay (Sigma-Aldrich), using BSA as standard.

2.5. Oxidative Refolding Assay. Oxidative refolding of denatured-reduced ribonuclease A (drRNAse) by recombinant amebic PDI enzymes was assayed by following a reported protocol [25]. Refolding was achieved by diluting drRNAse $(7.8 \mu \mathrm{M})$ into a reaction buffer $(2 \mathrm{mM}$ GSH, $0.4 \mathrm{mM}$ GSSG, $100 \mathrm{~mm}$ Tris- $\mathrm{HCl}, \mathrm{pH} 8.0)$ containing $5 \mu \mathrm{M}$ of amebic PDI enzymes and $4.5 \mathrm{mM}$ of cCMP (RNAse substrate). The reactivation of RNAse was followed for $60 \mathrm{~min}$ by recording the absorbance at $296 \mathrm{~nm}$. Active RNAse $(\mu \mathrm{M})$ was calculated from the first derivative of the absorbance over time and corrected for the depletion of the substrate and the formation of the product (CMP, RNAse inhibitor) [25]. The isomerase activity was determined from the linear increase of active RNAse over time $(\mu \mathrm{M} / \mathrm{min})$, after the lag phase (which reflects the oxidase activity, $\mathrm{min}^{-1}$ ).

2.6. Disulfide Reductase Assay. Disulfide reduction of bovine insulin catalyzed by recombinant amebic PDI enzymes was assayed according to a standard turbidity method [21, 26]. Recombinant enzymes ( $2 \mu \mathrm{M}$ final) were added to a reaction buffer ( 2 mM EDTA and 100 mM HEPES; pH 7.0) containing bovine insulin $(100 \mu \mathrm{M}$ final). Disulfide reduction was started by adding DTT $(0.3 \mathrm{mM}$ final) and followed for $90 \mathrm{~min}$ by recording the $A_{650}$ every $5 \mathrm{~min}$. Reductase activity was determined from the linear increase of absorbance over time after the lag phase $\left(A_{650} / \mathrm{min}^{2}\right)$ [27].

2.7. Chaperone Activity Assays. Chaperone-like activity of EhPDI was evaluated by performing a protection against 
thermal inactivation assay of two heat-labile enzymes: $\alpha$ glucosidase $[28,29]$ and $N d e I$ endonuclease $[30,31]$.

2.7.1. Thermal Inactivation of $\alpha$-Glucosidase. Different concentrations of EhPDI $(0-5 \mu \mathrm{M}$ final) were added to a reaction buffer $\left(50 \mathrm{mM} \mathrm{KH} \mathrm{PO}_{4} ; \mathrm{pH} 6.8\right)$ containing yeast $\alpha$ glucosidase $(16 \mu \mathrm{g} / \mathrm{mL}$ final). Thermal inactivation was performed by incubating at $43^{\circ} \mathrm{C}$ for $60 \mathrm{~min}$ (a control without treatment was carried out for each concentration). Then, reactions were cooled on ice for $1 \mathrm{~min}$ and the aggregated protein was separated by centrifugation ( $5 \mathrm{~min}$ at $14,500 \mathrm{rpm}$ ). $\alpha$-glucosidase activity was determined by diluting a $40 \mu \mathrm{L}$ aliquot of the supernatant with $160 \mu \mathrm{L}$ of reaction buffer containing $0.125 \mathrm{mM}$ of reduced glutathione and $1.25 \mathrm{mM}$ of $p$-nitrophenyl- $\alpha$-D-glucopyranoside. After 20 min of incubation at room temperature, reactions were stopped by adding $50 \mu \mathrm{L}$ of $0.5 \mathrm{M} \mathrm{Na}_{2} \mathrm{CO}_{3}$. The released $p$-nitrophenolate was quantified by measuring the absorbance at $415 \mathrm{~nm}$. The $\alpha$ glucosidase activity $(A G)$ was defined by the increase in absorbance over time $\left(A_{415} / \mathrm{min}\right)$. For each concentration of EhPDI, the percentage of protection against thermal inactivation (chaperone-like activity) was determined by using the following equation: protection $(\%)=\left(A G_{\mathrm{T}} / A G_{\mathrm{U}}\right) \times 100$, where $A G_{\mathrm{T}}$ represents the remaining $\alpha$-glucosidase activity after thermal treatment $\left(60 \mathrm{~min}\right.$ at $\left.43^{\circ} \mathrm{C}\right)$, while the untreated enzyme is represented by $A G_{\mathrm{U}}$.

2.7.2. Thermal Inactivation of NdeI Endonuclease. Different concentrations of EhPDI (0-2 $\mu \mathrm{M}$ final) were added to a reaction buffer $(75 \mathrm{mM}$ potassium acetate, $30 \mathrm{mM}$ Tris-acetate, $15 \mathrm{mM}$ magnesium acetate, $1.5 \mathrm{mM}$ DTT; $\mathrm{pH}$ 7.9) containing $\mathrm{NdeI}$ endonuclease $(1 \mathrm{U} / \mu \mathrm{L}$ final). Thermal inactivation was performed by incubating at $50^{\circ} \mathrm{C}$ for $30 \mathrm{~min}$ (control reactions without incubation were carried out). Then, the reactions were cooled on ice for $2 \mathrm{~min}$ and briefly centrifuged (to collect a $10 \mu \mathrm{L}$ volume). Endonucleolytic activity was determined by adding $5 \mu \mathrm{L}$ of a plasmid solution, containing $0.1 \mu \mathrm{g}$ of pUC19 and $0.1 \mathrm{mg}$ of BSA. After 2 hours of incubation at $37^{\circ} \mathrm{C}$, standard agarose gel electrophoresis and ethidium bromide staining were used to analyze the restriction fragments. The NdeI endonuclease activity was defined by the relative amount of linearized plasmid, estimated by digital densitometry. For each concentration of EhPDI, the percentage of protection against thermal inactivation (chaperonelike activity) was determined by using the following equation: protection $(\%)=\left[\left(E N_{\mathrm{T}}-\mathrm{C} 2\right) /(\mathrm{C} 1-\mathrm{C} 2)\right] \times 100$, where $E N_{\mathrm{T}}$ represents the remaining $\mathrm{NdeI}$ endonuclease activity after thermal treatment $\left(30 \mathrm{~min}\right.$ at $50^{\circ} \mathrm{C}$ ), while $\mathrm{Cl}$ (with $\mathrm{NdeI}$ ) and C2 (without NdeI) correspond to the control reactions without treatment.

2.8. Statistical Analysis. Unless otherwise mentioned, activity data were from three independent experiments and are represented as mean \pm standard error. All statistical analysis were performed using Prism v.5 (GraphPad Software, San Diego, CA). Unpaired $t$-test was used for routine comparison of data sets. $P$ values less than 0.05 were considered statistically significant.

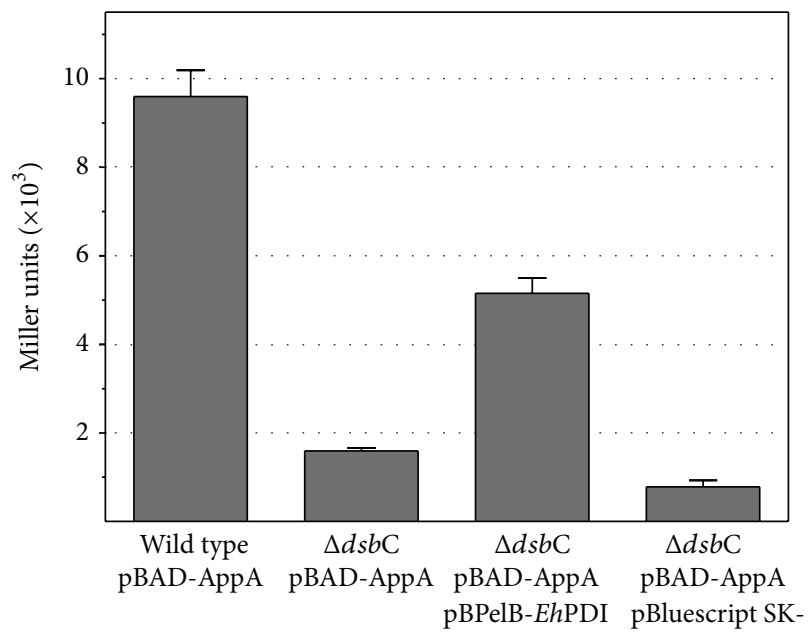

FIGURE 1: Acid phosphatase activity when AppA was expressed in the wild type and $\Delta d s b \mathrm{C}$ mutant strains, as well as when it was coexpressed with EhPDI in the $\Delta d s b \mathrm{C}$ mutant strain. The activity (expressed in Miller units) is shown on the left. The plasmids used for transfection of $E$. coli are also indicated.

\section{Results and Discussion}

3.1. EhPDI Exhibits In Vivo Isomerase Activity. To study the functional activities of eukaryotic PDI enzymes in vivo, yeast and bacterial cells have been successfully used to complement phenotypes associated with defective formation of disulfide bonds [32, 33]. In E. coli cells, the oxidative folding of polypeptides is carried out in the periplasmic compartment and performed by the Dsb proteins: oxidation and isomerization of disulfide bonds are catalyzed by DsbA and DsbC, respectively [34].

The DsbC protein is particularly notable since it shares structural and functional similarities with eukaryotic PDI enzymes [35]. In fact, its functional role as disulfide isomerase has been studied using eukaryotic multidisulfide proteins as substrates $[35,36]$. Four physiological substrates of DsbC have been identified so far: AppA [23], RcsF [37], MepA, and RNAse I [38]; from these, in vivo studies using AppA as substrate protein showed that DsbC plays an important role during folding of proteins with nonconsecutive disulfide bonds [23]. Then, to test whether EhPDI exhibits disulfide isomerase activity in vivo, we performed a functional complementation assay using the $\Delta d s b \mathrm{C}$ mutant of $E$. coli as a model and the defective periplasmic expression of AppA as the phenotype.

Initially, the absence of acid phosphatase activity (as background) was confirmed, indicating that the chromosomal appA gene was not induced under our experimental conditions (data not shown). Then, pBAD-AppA (Table 1) was used to transform both wild type and $\Delta d s b C$ mutant strains. Stable transformants were cultured and AppA expression was induced properly. As noted in Figure 1, a high level of acid phosphatase activity was detected in the wild type strain, $9595 \pm 593$ Miller units, whereas a low level of activity was observed in the $\Delta d s b \mathrm{C}$ mutant $(1593 \pm 70$ Miller units), confirming the DsbC-dependence of AppA (Figure 1). 
TABLE 2: In vivo isomerase activity of EhPDI enzyme variants.

\begin{tabular}{lc}
\hline Enzyme variant & $\begin{array}{c}\text { Acid phosphatase (AppA) } \\
\text { activity in Miller units (\%) }\end{array}$ \\
\hline EhPDI $_{\mathrm{SS} / \mathrm{SS}}$ & $732 \pm 74(-1)$ \\
EhPDI $_{\mathrm{SS} / \mathrm{CC}}$ & $1086 \pm 136(7)$ \\
hhPDI $_{\mathrm{CC} / \mathrm{SS}}$ & $1646 \pm 230(20)$ \\
\hline
\end{tabular}

* The data was expressed as \pm standard error $(n=6)$.

IUnder the background of $\Delta d s b \mathrm{C} / \mathrm{pBAD}$-AppA, normalization was performed considering the mean activity of pBPelB-EhPDI as maximal $\left(A_{\max }\right.$ $=5151)$ and pBluescript SK- as minimal $\left(A_{\min }=780\right)$. The percentage $(\%)$ was calculated as $\left[\left(A-A_{\min }\right) /\left(A_{\max }-A_{\min }\right)\right] \times 100$, where $A$ represents the activity of the enzyme variant.

Then, pBPelB-EhPDI (Table 1) was used to transform the $\Delta d s b \mathrm{C} / \mathrm{pBAD}-\mathrm{AppA}$ strain, using a two-plasmid system [39]. Stable cotransformants were cultured and protein expression was induced accordingly. Periplasmic expression of EhPDI was confirmed by immunoblot (data not shown). Interestingly, a significant increase in acid phosphatase activity was detected (5151 \pm 344 Miller units), suggesting that the correct disulfide bond formation of AppA was assisted by the isomerase activity of EhPDI.

\subsection{Isomerase Activity of EhPDI Is Limited and Dependent on} Its Reductase Activity. The active site of the thioredoxin-like domains from DsbA, DsbC, and PDI enzymes is characterized by the presence of the motif CXXC, where the cysteine residues play an important role in the enzymatic activity [40, 41]. EhPDI contains two thioredoxin-like domains (referred to as $\mathrm{N}$ - and C-Trx, resp.; both having the motif CGHC) that are essential for its in vivo oxidase activity [20]. To test whether both domains contribute to the isomerase activity, we carried out mutagenic analysis followed by a functional complementation assay.

The pBluescript-based plasmids expressing EhPDI variants (Table 1) were used to transform the $\Delta d s b \mathrm{C} / \mathrm{pBAD}-\mathrm{AppA}$ strain. Stable cotransformants were cultured and protein expression was induced accordingly. Periplasmic expression of EhPDI variants was confirmed by immunoblot (data not shown). As indicated in Table 2, the isomerase activity of EhPDI is dependent on its CGHC active sites, since a complete loss of the AppA activity was observed when the variant having both domains inactivated was coexpressed $\left(E h \mathrm{PDI}_{\mathrm{SS} / \mathrm{sS}}\right)$. Also, low AppA activity was detected when each domain was tested without the background of the other $\left(E h \mathrm{PDI}_{\mathrm{SS} / \mathrm{CC}}\right.$ and $E h \mathrm{PDI}_{\mathrm{CC} / \mathrm{SS}}$ ); furthermore, the slight difference observed between these two variants can be explained by considering that the thioredoxin-like domains are not equivalent with regard to the isomerase activity [33, 42]. However, it is important to take into account the cellular features of the bacterial model to better understand the role of EhPDI as an isomerase in vivo.

In the periplasmic compartment, substrate proteins with misoxidized disulfide bonds are shuffled to properly oxidized states by two mechanisms: (1) the isomerase pathway, where DsbC acts on the substrate as reductase-oxidase, and (2) the reductase pathway, where DsbC simply acts as reductase,
TABLE 3: In vitro activities of purified EhPDI enzyme variants.

\begin{tabular}{lccc}
\hline & \multicolumn{2}{c}{ RNAse A oxidative refolding } \\
Enzyme & $\begin{array}{c}\text { Oxidase } \\
{\left[\times 10^{-6} \mathrm{~min}^{-1}\right]} \\
(\%)\end{array}$ & $\begin{array}{c}\text { Isomerase } \\
{\left[\times 10^{-6} \mu \mathrm{M} / \mathrm{min}\right]} \\
(\%)\end{array}$ & $\begin{array}{c}\text { Insulin reduction } \\
{\left[\times 10^{-6} A_{650} / \mathrm{min}^{2}\right]} \\
(\%)\end{array}$ \\
\hline EhPDI & $513 \pm 16(100)$ & $39 \pm 1(100)$ & $109 \pm 11(100)$ \\
EhPDI $_{\text {SS/CC }} 551 \pm 16(107)$ & $33 \pm 1(85)$ & $22 \pm 2(20)$ \\
EhPDI $_{\text {CC/SS }} 517 \pm 13(101)$ & $31 \pm 1(79)$ & $65 \pm 5(60)$ \\
\hline
\end{tabular}

${ }^{*}$ The data was expressed as mean \pm standard error $(n=3)$.

${ }^{\dagger}$ The activity of the enzyme variant $E h \mathrm{PDI}_{\mathrm{SS} / \mathrm{SS}}$ was not statistically significant, as compared with the reaction performed in the absence of enzyme.

'The activity ratio (\%) was calculated as (variant/wild type) $\times 100$.

allowing DsbA another chance to correctly oxidize the substrate [43]. In addition, when the $\Delta d s b C$ mutant of $E$. coli was complemented with the protein TrxP from Bacteroides fragilis (a periplasmic reductase with poor isomerase activity), a fully restored AppA activity was observed, indicating that the disulfide bond isomerization of this substrate is accomplished mainly through the reductase pathway [43]. Hence, it is reasonable to think that the low AppA activity detected when the $\Delta d s b C$ mutant of $E$. coli was complemented with any of the variants (Table 2) suggests that the isomerase function of EhPDI is dependent on its reductase activity. To test this, we performed two in vitro activity assays, oxidative refolding of ribonuclease and reduction of insulin, using purified recombinant enzymes, that is, EhPDI variants.

As indicated in Table 3, the wild type (EhPDI) and variants $\left(E h \mathrm{PDI}_{\mathrm{SS} / \mathrm{CC}}\right.$ and $\left.E h \mathrm{PDI}_{\mathrm{CC} / \mathrm{SS}}\right)$ showed comparable oxidative refolding capabilities. In contrast, significant differences were observed in their reductive activities: $E h \mathrm{PDI}_{\mathrm{CC} / \mathrm{SS}}$ retained about $60 \%$, whilst $E h \mathrm{PDI}_{\mathrm{SS} / \mathrm{CC}}$ roughly retained $20 \%$. These results confirmed that EhPDI is dependent on its reductase activity to function as oxidoreductase in vivo and in vitro.

3.3. EhPDI Protects Proteins against Thermal-Induced Aggregation. The chaperone-like function of PDI enzymes is determined by their ability to protect misfolded/unfolded substrate proteins against thermal-induced aggregation and to assist refolding $[44,45]$. This function is essential in order for PDI to act as an efficient folding catalyst, since it allows access to buried thiols and disulfide bonds in the substrates and prevents nonspecific interactions between partially folded intermediates [1]. Typically, the chaperone-like function has been studied in vitro by measuring the ability to prevent protein aggregation induced by different physical or chemical conditions, such as temperature or denaturants $[5,46]$.

We have already reported that EhPDI exhibits chaperonelike function by showing its ability to prevent the DTTinduced aggregation of the B chain of insulin [21]. Although this assay was a simple approach to test the chaperonelike function of EhPDI, the low molecular mass of the substrate $(3.4 \mathrm{kDa})$ represents a limitation of this assay, since it offers a restricted number of contact sites to form stable complexes [47]. Hence, to gain further insights regarding the 


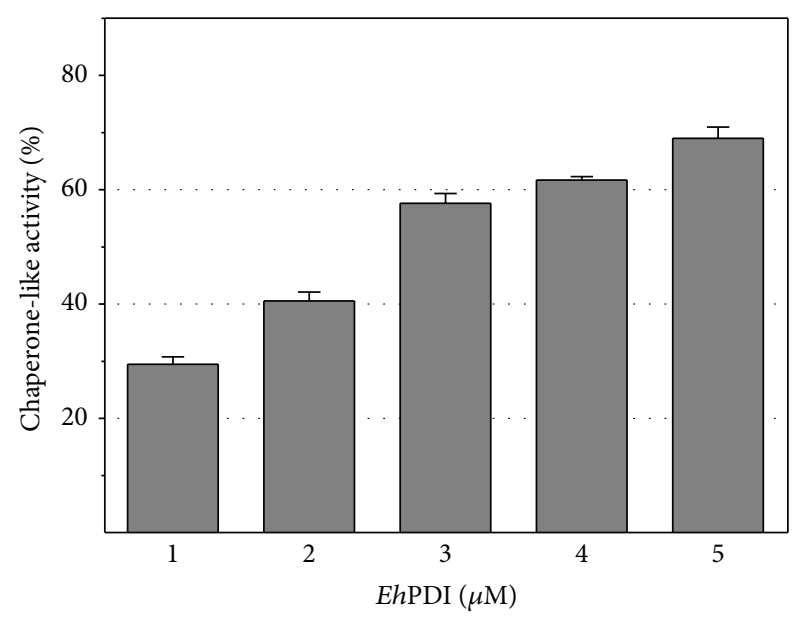

FIgURE 2: Protection of thermal inactivation of $\alpha$-glucosidase assisted by EhPDI. Relative chaperone-like activity (\%) of recombinant EhPDI.
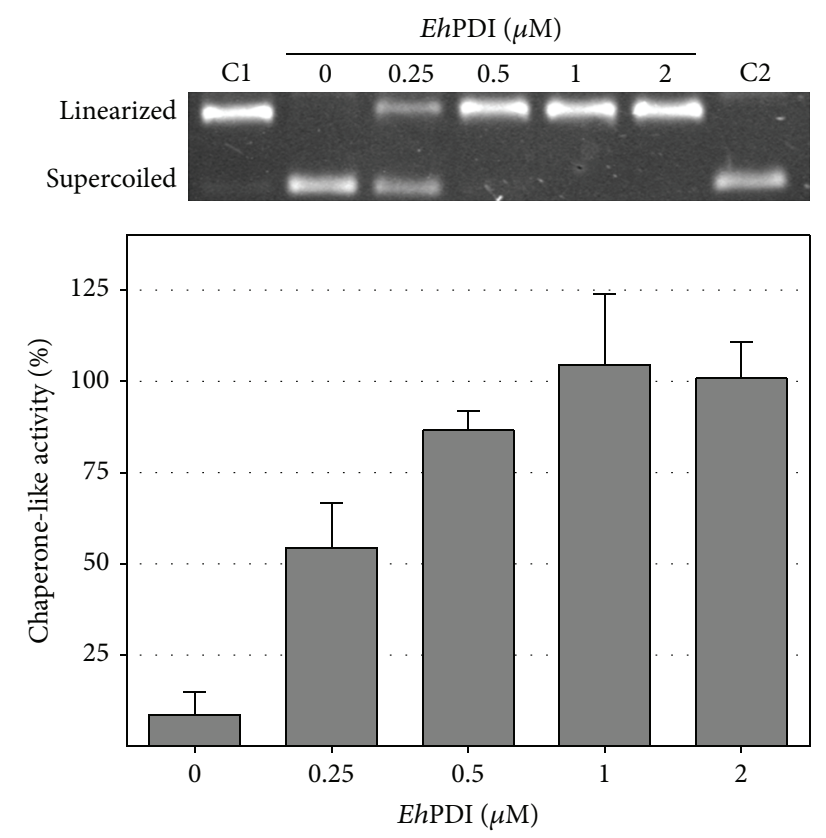

FIgure 3: Protection of thermal inactivation of NdeI endonuclease assisted by EhPDI. Relative chaperone-like activity (\%) of recombinant EhPDI. Upper panel: agarose gel indicating the relative mobility of the linearized and supercoiled plasmid ( $\mathrm{Cl}$ and $\mathrm{C} 2$ ); also, concentrations of EhPDI are indicated.

chaperone-like function of EhPDI, we performed additional in vitro assays to test its ability to prevent thermal-induced aggregation, using as substrates two heat-labile enzymes: $\alpha$ glucosidase and NdeI endonuclease.

As shown in Figures 2 and 3, the chaperone-like function of EhPDI was dose-dependent, since an increment of activity was observed as a result of augmenting its concentration. Moreover, to estimate its chaperone-like ability, the halfmaximal effective concentration $\left(\mathrm{EC}_{50}\right)$ and Hill slope were calculated by fitting the data to a model of one specific binding site with a variable slope. Interestingly, the apparent values obtained for $\alpha$-glucosidase $\left(\mathrm{EC}_{50}=3.0 \pm 0.4 \mu \mathrm{M}\right.$; Hill slope $=1.0)$ and $N d e \mathrm{I}$ endonuclease $\left(\mathrm{EC}_{50}=0.26 \pm 0.06 \mu \mathrm{M}\right.$; Hill slope $=2.4)$ suggest that EhPDI exhibits differences in substrate specificity and affinity [48].

Although EhPDI does not have a substrate-binding $b^{\prime}$ domain $\left(a-a^{\prime}-D\right)$ as the mammalian homologue $\left(a-b-b^{\prime}-a^{\prime}-c\right)$ [49], the notion that some other domains (e.g., $\mathrm{a}^{\prime}$ or D) might be involved in the chaperone activity is evident. This idea is supported by the results of two previous reports: (i) ERp46, which lacks a $b^{\prime}$-domain, is able to bind peptides through its catalytic domains $\left(\mathrm{a}^{0}, \mathrm{a}\right.$, and $\left.\mathrm{a}^{\prime}\right)[50]$ and (ii) the D-domain of ERp29 contains a discrete and conserved substrate-binding site [51].

3.4. Closing Remarks. Although little is known about the $E$. histolytica mechanisms that act in response to proteotoxic stress [52], the upregulation of genes encoding typical chaperones (such as Hsp70 and Hsp90) in a response to thermal stress suggests that it contains the cellular machinery necessary to preserve and restore the stability of the proteome [53]. So, the identification and characterization of EhPDI as a folding catalyst with chaperone-like activity represents an additional step to dissect the molecular mechanisms involved in both protein folding and proteotoxic stress in E. histolytica. Hence, it is conceivable to suppose that inhibition of EhPDI could lead to an increase in protein misfolding, promoting a sustained proteotoxic stress, eventually inducing apoptosis and, thus, preventing infection by this parasite.

\section{Conflict of Interests}

The authors declare that there is no conflict of interests regarding the publication of this paper.

\section{Acknowledgments}

This work was supported in part by Grants from PROMEP (NPTC-103.5/11/3713 to Rosa E. Mares), UABC (CGPICI17/3878 to Samuel G. Meléndez-López), and CONACYT (CB-2010/01/155714 and SSA/IMSS/ISSSTE-2011/01/161544 to Marco A. Ramos). Rosa E. Mares, Samuel G. MeléndezLópez, and Marco A. Ramos are National Researchers (SNICONACYT, Mexico) and members of the Biological-Pharmaceutical Academic Group (Health Sciences, UABC).

\section{References}

[1] S. Imaoka, "Chemical stress on protein disulfide isomerases and inhibition of their functions," International Review of Cell and Molecular Biology, vol. 290, pp. 121-166, 2011.

[2] K. Inaba, "Structural basis of protein disulfide bond generation in the cell," Genes to Cells, vol. 15, no. 9, pp. 935-943, 2010.

[3] C. S. Sevier and C. A. Kaiser, "Conservation and diversity of the cellular disulfide bond formation pathways," Antioxidants \& Redox Signaling, vol. 8, no. 5-6, pp. 797-811, 2006.

[4] K. Denoncin and J.-F. Collet, "Disulfide bond formation in the bacterial periplasm: major achievements and challenges ahead," Antioxidants and Redox Signaling, vol. 19, no. 1, pp. 63-71, 2013. 
[5] S. Xu, S. Sankar, and N. Neamati, "Protein disulfide isomerase: a promising target for cancer therapy," Drug Discovery Today, vol. 19, no. 3, pp. 222-240, 2014.

[6] F. Hatahet and L. W. Ruddock, "Protein disulfide isomerase: a critical evaluation of its function in disulfide bond formation," Antioxidants and Redox Signaling, vol. 11, no. 11, pp. 2807-2850, 2009.

[7] B. Selles, J.-P. Jacquot, and N. Rouhier, "Comparative genomic study of protein disulfide isomerases from photosynthetic organisms," Genomics, vol. 97, no. 1, pp. 37-50, 2011.

[8] J. J. Galligan and D. R. Petersen, "The human protein disulfide isomerase gene family," Human Genomics, vol. 6, article 6, 2012.

[9] H. Urra, E. Dufey, F. Lisbona, D. Rojas-Rivera, and C. Hetz, "When ER stress reaches a dead end," Biochimica et Biophysica Acta: Molecular Cell Research, vol. 1833, no. 12, pp. 3507-3517, 2013.

[10] K. Niforou, C. Cheimonidou, and I. P. Trougakos, "Molecular chaperones and proteostasis regulation during redox imbalance," Redox Biology, vol. 2, no. 1, pp. 323-332, 2014.

[11] S. Lee, S. Min Kim, J. Dotimas et al., "Thioredoxin-interacting protein regulates protein disulfide isomerases and endoplasmic reticulum stress," EMBO Molecular Medicine, vol. 6, no. 6, pp. 732-743, 2014.

[12] C. Muller, J. Bandemer, C. Vindis et al., "Protein disulfide isomerase modification and inhibition contribute to ER stress and apoptosis induced by oxidized low density lipoproteins," Antioxidants and Redox Signaling, vol. 18, no. 7, pp. 731-742, 2013.

[13] R. Jasuja, F. H. Passam, D. R. Kennedy et al., "Protein disulfide isomerase inhibitors constitute a new class of antithrombotic agents," The Journal of Clinical Investigation, vol. 122, no. 6, pp. 2104-2113, 2012.

[14] S. Xu, A. N. Butkevich, R. Yamada et al., "Discovery of an orally active small-molecule irreversible inhibitor of protein disulfide isomerase for ovarian cancer treatment," Proceedings of the National Academy of Sciences of the United States of America, vol. 109, no. 40, pp. 16348-16353, 2012.

[15] C. Ximénez, P. Morán, L. Rojas, A. Valadez, and A. Gómez, "Reassessment of the epidemiology of amebiasis: state of the art," Infection, Genetics and Evolution, vol. 9, no. 6, pp. 10231032, 2009.

[16] A. Olivos-García, E. Saavedra, E. Ramos-Martínez, M. Nequiz, and R. Pérez-Tamayo, "Molecular nature of virulence in Entamoeba histolytica," Infection, Genetics and Evolution, vol. 9, no. 6, pp. 1033-1037, 2009.

[17] L. Barroso, M. Abhyankar, Z. Noor et al., "Expression, purification, and evaluation of recombinant LecA as a candidate for an amebic colitis vaccine," Vaccine, vol. 32, no. 10, pp. 1218-1224, 2014.

[18] O. Hecht, N. A. van Nuland, K. Schleinkofer et al., "Solution structure of the pore-forming protein of Entamoeba histolytica," Journal of Biological Chemistry, vol. 279, no. 17, pp. 17834-17841, 2004.

[19] M. A. Ramos, R. E. Mares, P. D. Magaña, J. E. Ortega, and J. M. Cornejo-Bravo, "In silico identification of the protein disulfide isomerase family from a protozoan parasite," Computational Biology and Chemistry, vol. 32, no. 1, pp. 66-70, 2008.

[20] R. E. Mares, P. D. Magaña, S. G. Meléndez-López, A. F. Licea, J. M. Cornejo-Bravo, and M. A. Ramos, "Oxidative folding and reductive activities of EhPDI, a protein disulfide isomerase from Entamoeba histolytica," Parasitology International, vol. 58, no. 3, pp. 311-313, 2009.
[21] M. A. Ramos, R. E. Mares, P. D. Magaña, I. D. Rivas, and S. G. Meléndez-López, "Entamoeba histolytica: biochemical characterization of a protein disulfide isomerase," Experimental Parasitology, vol. 128, no. 1, pp. 76-81, 2011.

[22] M. A. Ramos, R. Sanchez-Lopez, R. E. Mares, F. Olvera, and A. Alagón, "Identification of an Entamoeba histolytica gene encoding a protein disulfide isomerase that functionally complements the $d s b A$ mutation in Escherichia coli," Molecular and Biochemical Parasitology, vol. 143, no. 2, pp. 236-240, 2005.

[23] M. Berkmen, D. Boyd, and J. Beckwith, "The nonconsecutive disulfide bond of Escherichia coli phytase (AppA) renders it dependent on the protein-disulfide isomerase, DsbC," The Journal of Biological Chemistry, vol. 280, no. 12, pp. 11387-11394, 2005.

[24] J. H. Miller, A Short Course in Bacterial Genetics, CSHL Press, Cold Spring Harbor, NY, USA, 1992.

[25] B. Wilkinson, R. Xiao, and H. F. Gilbert, "A structural bisulfide of yeast protein-disulfide isomerase destabilizes the active site disulfide of the N-terminal thioredoxin domain," Journal of Biological Chemistry, vol. 280, no. 12, pp. 11483-11487, 2005.

[26] A. Holmgren, "Thioredoxin catalyzes the reduction of insulin disulfides by dithiothreitol and dihydrolipoamide," The Journal of Biological Chemistry, vol. 254, no. 19, pp. 9627-9632, 1979.

[27] E. Martinez-Galisteo, C. A. Padilla, C. Garcia-Alfonso, J. LopezBarea, and J. A. Barcena, "Purification and properties of bovine thioredoxin system," Biochimie, vol. 75, no. 9, pp. 803-809, 1993.

[28] T. Stromer, M. Ehrnsperger, M. Gaestel, and J. Buchner, "Analysis of the interaction of small heat shock proteins with unfolding proteins," The Journal of Biological Chemistry, vol. 278, no. 20, pp. 18015-18021, 2003.

[29] R. Kern, A. Malki, A. Holmgren, and G. Richarme, "Chaperone properties of Escherichia coli thioredoxin and thioredoxin reductase," Biochemical Journal, vol. 371, no. 3, pp. 965-972, 2003.

[30] M. Suragani, V. D. Aadinarayana, A. B. Pinjari et al., "Human resistin, a proinflammatory cytokine, shows chaperone-like activity," Proceedings of the National Academy of Sciences of the United States of America, vol. 110, no. 51, pp. 20467-20472, 2013.

[31] J. F. Hess and P. G. FitzGerald, "Protection of a restriction enzyme from heat inactivation by [alpha]-crystallin," Molecular Vision, vol. 4, article 29, 1998.

[32] T. Kimura, Y. Hosoda, Y. Kitamura, H. Nakamura, T. Horibe, and M. Kikuchi, "Functional differences between human and yeast protein disulfide isomerase family proteins," Biochemical and Biophysical Research Communications, vol. 320, no. 2, pp. 359-365, 2004.

[33] S. J. Stafford and P. A. Lund, "Mutagenic studies on human protein disulfide isomerase by complementation of Escherichia colidsbA and $d s b C$ mutants," FEBS Letters, vol. 466, no. 2-3, pp. 317-322, 2000.

[34] A. Rietsch, D. Belin, N. Martin, and J. Beckwith, "An in vivo pathway for disulfide bond isomerization in Escherichia coli," Proceedings of the National Academy of Sciences of the United States of America, vol. 93, no. 23, pp. 13048-13053, 1996.

[35] A. Rietsch, P. Bessette, G. Georgiou, and J. Beckwith, "Reduction of the periplasmic disulfide bond isomerase, DsbC, occurs by passage of electrons from cytoplasmic thioredoxin," Journal of Bacteriology, vol. 179, no. 21, pp. 6602-6608, 1997.

[36] P. H. Bessette, J. Qiu, J. C. A. Bardwell, J. R. Swartz, and G. Georgiou, "Effect of sequences of the active-site dipeptides of DsbA and DsbC on in vivo folding of multidisulfide proteins in 
Escherichia coli," Journal of Bacteriology, vol. 183, no. 3, pp. 980988, 2001.

[37] P. Leverrier, J.-P. Declercq, K. Denoncin et al., "Crystal structure of the outer membrane protein RcsF, a new substrate for the periplasmic protein-disulfide isomerase DsbC," The Journal of Biological Chemistry, vol. 286, no. 19, pp. 16734-16742, 2011.

[38] A. Hiniker and J. C. A. Bardwell, "In vivo substrate specificity of periplasmic disulfide oxidoreductases," Journal of Biological Chemistry, vol. 279, no. 13, pp. 12967-12973, 2004.

[39] K. Skowronek and A. A. Kasprzak, "A two-plasmid system for independent genetic manipulation of subunits of homodimeric proteins and selective isolation of chimeric dimers," Analytical Biochemistry, vol. 300, no. 2, pp. 185-191, 2002.

[40] H. Kadokura and J. Beckwith, "Mechanisms of oxidative protein folding in the bacterial cell envelope," Antioxidants and Redox Signaling, vol. 13, no. 8, pp. 1231-1246, 2010.

[41] A. R. Karala, A. K. Lappi, and L. W. Ruddock, "Modulation of an active-site cysteine pka allows pdi to act as a catalyst of both disulfide bond formation and isomerization," Journal of Molecular Biology, vol. 396, no. 4, pp. 883-892, 2010.

[42] M. M. Lyles and H. F. Gilber, "Mutations in the thioredoxin sites of protein disulfide isomerase reveal functional nonequivalence of the N- and C-terminal domains," Journal of Biological Chemistry, vol. 269, no. 49, pp. 30946-30952, 1994.

[43] S. R. Shouldice, S.-H. Cho, D. Boyd et al., "In vivo oxidative protein folding can be facilitated by oxidation-reduction cycling," Molecular Microbiology, vol. 75, no. 1, pp. 13-28, 2010.

[44] M. Taylor, H. Burress, T. Banerjee et al., "Substrate-induced unfolding of protein disulfide isomerase displaces the cholera toxin Al subunit from its holotoxin," PLoS Pathogens, vol. 10, no. 2, Article ID e1003925, 2014.

[45] R. Tian, S.-J. Li, D.-L. Wang, Z. Zhao, Y. Liu, and R.-Q. He, “The acidic C-terminal domain stabilizes the chaperone function of protein disulfide isomerase," Journal of Biological Chemistry, vol. 279, no. 47, pp. 48830-48835, 2004

[46] R. Chaudhuri, Y. Cheng, C. R. Middaugh, and D. B. Volkin, "High-throughput biophysical analysis of protein therapeutics to examine interrelationships between aggregate formation and conformational stability," AAPS Journal, vol. 16, no. 1, pp. 48-64, 2014.

[47] X.-M. Fu and B. T. Zhu, "Human pancreas-specific protein disulfide-isomerase (PDIp) can function as a chaperone independently of its enzymatic activity by forming stable complexes with denatured substrate proteins," Biochemical Journal, vol. 429, no. 1, pp. 157-169, 2010.

[48] A. G. Irvine, A. K. Wallis, N. Sanghera et al., "Protein disulfideisomerase interacts with a substrate protein at all stages along its folding pathway," PLoS ONE, vol. 9, no. 1, Article ID e82511, 2014.

[49] L. J. Bryne, A. Sidhu, A. K. Wallis et al., "Mapping of the ligandbinding site on the b' domain of human PDI: interaction with peptide ligands and the x-linker region," Biochemical Journal, vol. 423, no. 2, pp. 209-217, 2009.

[50] A. Funkner, C. Parthier, M. Schutkowski et al., "Peptide binding by catalytic domains of the protein disulfide isomerase-related protein ERp46," Journal of Molecular Biology, vol. 425, no. 8, pp. 1340-1362, 2013.

[51] U. Lippert, D. Diao, N. N. Barak, and D. M. Ferrari, “Conserved structural and functional properties of D-domain containing redox-active and -inactive protein disulfide isomerase-related protein chaperones," The Journal of Biological Chemistry, vol. 282, no. 15, pp. 11213-11220, 2007.
[52] J. Santi-Rocca, S. Smith, C. Weber et al., "Endoplasmic reticulum stress-sensing mechanism is activated in Entamoeba histolytica upon treatment with nitric oxide," PLoS ONE, vol. 7, no. 2, Article ID e31777, 2012.

[53] C. Weber, G. Guigon, C. Bouchier et al., "Stress by heat shock induces massive down regulation of genes and allows differential allelic expression of the Gal/GalNAc lectin in Entamoeba histolytica," Eukaryotic Cell, vol. 5, no. 5, pp. 871-875, 2006.

[54] T. Baba, T. Ara, M. Hasegawa et al., "Construction of Escherichia coli K-12 in-frame, single-gene knockout mutants: the Keio collection," Molecular Systems Biology, vol. 2, Article ID 2006.0008, 2006.

[55] L.-M. Guzman, D. Belin, M. J. Carson, and J. Beckwith, “Tight regulation, modulation, and high-level expression by vectors containing the arabinose $\mathrm{P}(\mathrm{BAD})$ promoter," Journal of Bacteriology, vol. 177, no. 14, pp. 4121-4130, 1995. 

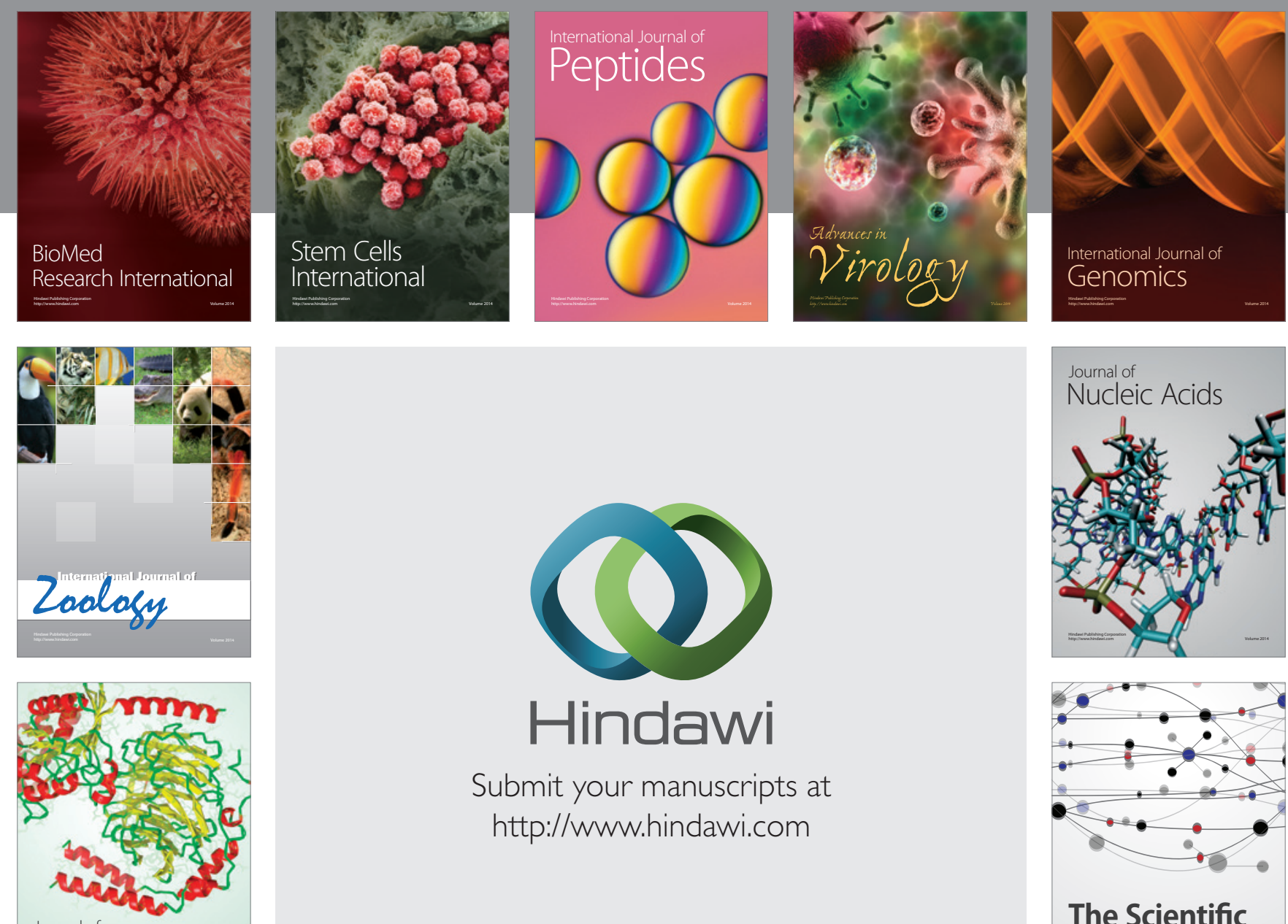

Submit your manuscripts at

http://www.hindawi.com

Journal of
Signal Transduction
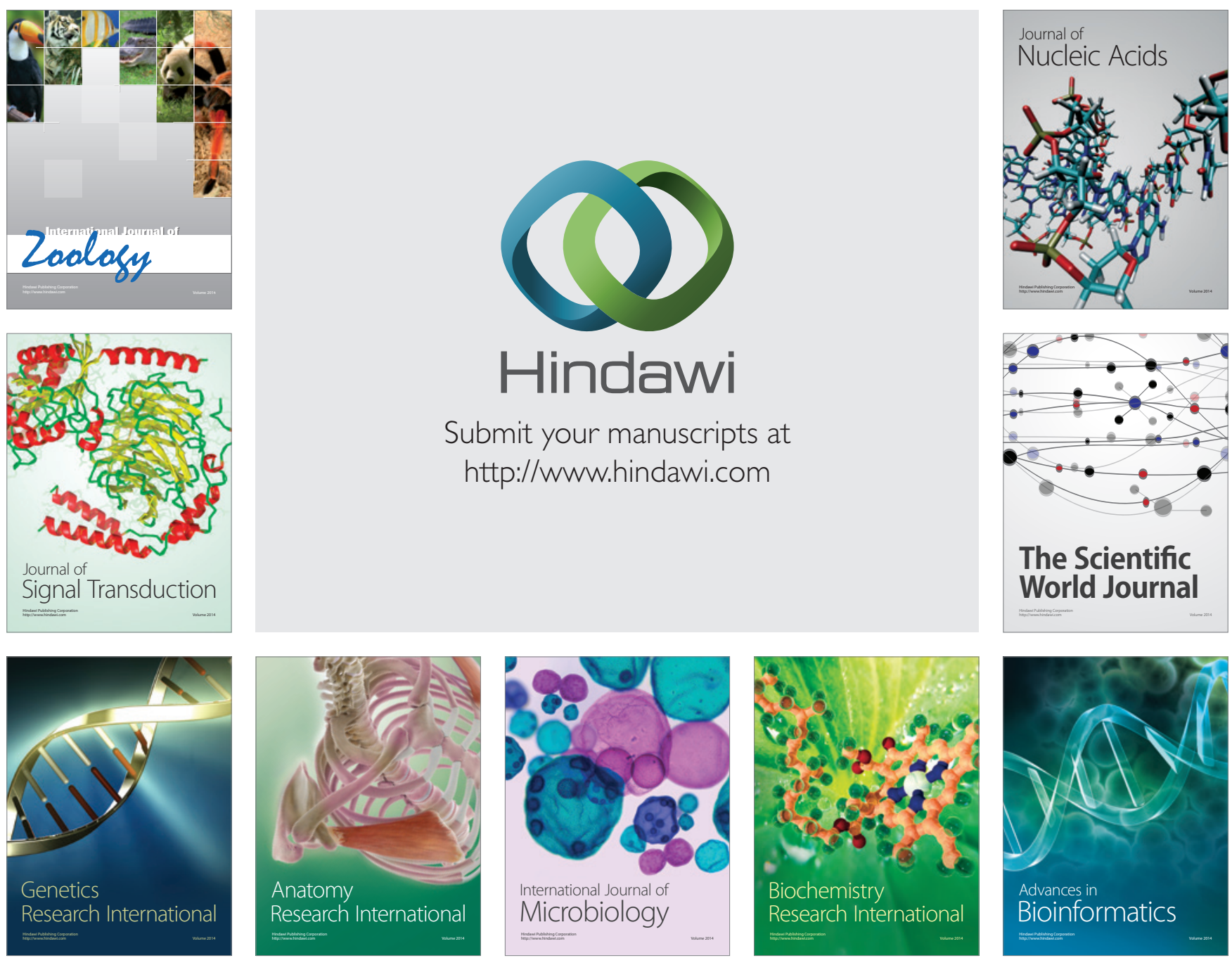

The Scientific World Journal
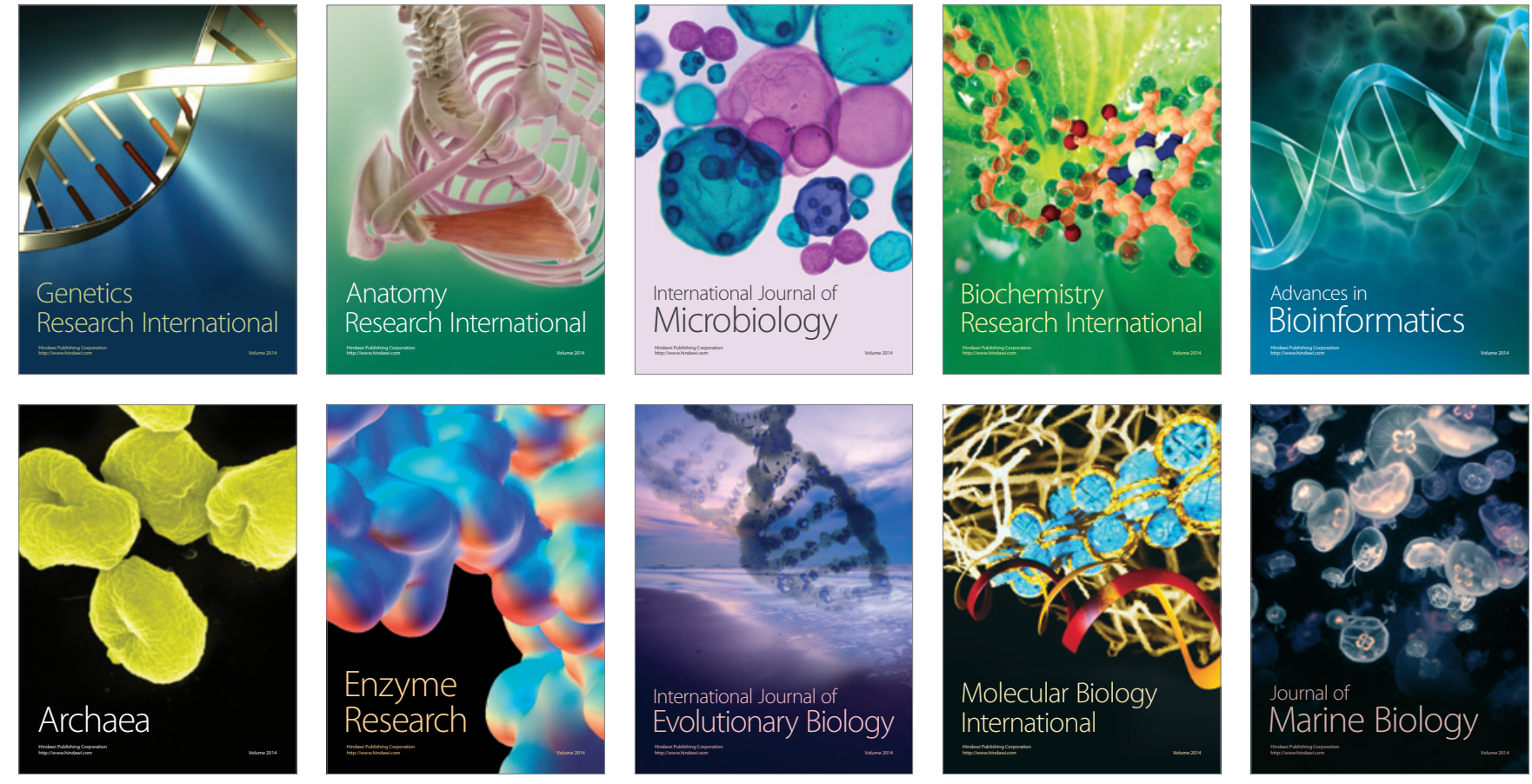